\title{
THE CORRELATION BETWEEEN EXPOSURE TO CARBON MONOXIDE AND HEMOGLOBIN LEVEL AMONG STREET FOOD VENDORS AT GLADAG MARKET, SURAKARTA, CENTRAL JAVA
}

\author{
Haris Setyawan, Nafilatul Fitri, Ipop Sjarifah, Khotijah \\ Department of Occupational Health, Hygiene, and Safety, \\ Faculty of Medicine, Sebelas Maret University
}

\begin{abstract}
BACKGROUND: Carbon monoxide (CO) is an emission that comes from incomplete combustion of oxygen and fuel in vehicles. Carbon monoxide can affect human health. It binds hemoglobin $(\mathrm{Hb})$ to form $\mathrm{COHb}$ bond. People who work near heavy traffic are at risk for $\mathrm{CO}$ exposure. This study aimed to examine the correlation between exposure to carbon monoxide and hemoglobin level among street food vendors at Gladag food market, Surakarta.

SUBJECT AND METHODS: This was an analytic observational study with cross-sectional design. A random sample of 38 street food vendors at Gladag food market Surakarta. Carbon monoxide was measured by CO meter. Hemoglobin was measured by spectrophotometry. Spearman correlation was used to show the correlation between exposure to carbon monoxide and hemoglobin level among street food vendors.

RESULTS: There was positive weak correlation between exposure to carbon monoxide and hemoglobin level among street food vendors, and it was not statistically significant $(\mathrm{r}=0.15 ; \mathrm{p}=0.362)$.

CONCLUSION: There was positive weak correlation between exposure to carbon monoxide and hemoglobin level among street food vendors.
\end{abstract}

Keywords: Carbon monoxide, exposure, hemoglobin, street food vendors 